\title{
DECISÕES DE INVESTIMENTO E MOVIMENTOS DE REESTRUTURAÇÃO: UM MODELO DE ANÁLISE DA INDÚSTRIA PETROQUÍMICA *
}

\author{
Francisco Teixeira ${ }^{* *}$
}

Oswaldo Guerra ${ }^{* * *}$

\section{Luiz Ricardo Cavalcante}

RESUMO O objetivo deste artigo é apresentar um modelo de análise das decisões de investimentos na indústria petroquímica, destacando as principais variáveis que as têm motivado e induzido os movimentos de reestruturação no setor. O modelo estrutura/conduta/desempenho (ECD), largamente usado na literatura de economia industrial, e as características estruturais da indústria petroquímica embasam o modelo analítico proposto. A aplicação do modelo para o período iniciado em 2000 revelou que, no conjunto das variáveis identificadas, o acesso às matérias-primas e aos mercados com maior potencial de crescimento tem sido aquele com maior capacidade para desencadear os movimentos de reestruturação da indústria petroquímica no período recente.

Palavras-chave: decisões de investimento; estrutura de mercado; estratégias empresariais, forças de mudança; indústria petroquímica

Código JEL: L11

* Artigo recebido em 11 de maio de 2009 e aprovado em 10 de setembro de 2009.

** Doutor pela Universidade de Sussex (Inglaterra) e professor titular da Escola de Administração da Universidade Federal da Bahia (UFBA), e-mail: teixeira@ufba.br

*** Doutor pela Universidade de Campinas (Unicamp) e professor associado da Faculdade de Ciências Econômicas da Universidade Federal da Bahia (UFBA), e-mail: oguerra@ufba.br

$\star * * *$ Doutor pela Universidade Federal da Bahia (UFBA) e técnico de planejamento e pesquisa do Instituto de Pesquisa Econômica Aplicada (Ipea), e-mail: ricardo.cavalcante@ipea.gov.br 


\section{INVESTMENT DECISIONS AND RESTRUCTURING MOVEMENTS:} A MODEL OF ANALYSIS OF THE PETROCHEMICAL INDUSTRY

ABSTRACT The aim of this paper is to propose a model of analysis of the investment decisions in the petrochemical industry highlighting the main variables which have bringing them about and causing the restructuring movements in the sector. The structure/conduct/ performance (SCP) model (widely used in the industrial economics literature) as well as the structural characteristics of the petrochemical industry support the analytical model proposed in this work. The application of the model to the period from 2000 onwards showed that, among the proposed variables, the access to raw material and to the most dynamic markets came out to be the most important ones to launch restructuring movements in the petrochemical industry.

Key words: investment decisions; market structures; firm strategies; driving forces; petrochemical industry 


\section{INTRODUÇÃO}

As decisões de investimentos e a estrutura da indústria petroquímica estão associadas a um conjunto de fatores que incluem aspectos de natureza econômica e tecnológica, políticas públicas e as próprias estratégias dos grupos empresariais que detêm ativos no setor. Esses fatores sofrem um permanente processo de alteração, motivando, em determinadas circunstâncias, movimentos de reestruturação como fusões, aquisições, joint ventures, spin-offs e a implantação de novas unidades de produção. Embora esses eventos tenham um impacto representativo na estrutura do setor e, em geral, envolvam somas expressivas, um referencial teórico especificamente voltado para a compreensão dos fatores que os desencadeiam no âmbito da indústria petroquímica não é facilmente encontrado, uma vez que os trabalhos sobre o tema são predominantemente descritivos. ${ }^{1}$

Diante dessa constatação, o objetivo deste artigo é apresentar um modelo de análise das decisões de investimentos na indústria petroquímica, destacando as principais variáveis que as têm motivado e induzido os movimentos de reestruturação no setor. Em linhas gerais, assume-se que algumas forças de mudanças, cuja origem são as condições básicas de oferta e demanda e as políticas governamentais, delimitam a estrutura da indústria e fornecem elementos para a compreensão das estratégias empresariais. Dessa forma, as forças de mudança que desencadeiam os movimentos de reestruturação não são consideradas exógenas, mas endógenas e particulares de cada mercado.

Essa percepção define o encadeamento lógico do artigo, segmentado em quatro seções. Na seção 1, os movimentos de reestruturação são conceituados e o modelo estrutura/conduta/desempenho, largamente usado na literatura de economia industrial, é revisto. Na seção 2, as características estruturais e os padrões de comércio da indústria petroquímica são apresentados. Em seguida, na seção 3, o modelo analítico é discutido. Propõe-se uma combinação do modelo ECD com as características estruturais e os padrões de comércio do setor expostos na seção anterior. Em seguida, as decisões de investimentos que resultam em movimentos concretos de reestruturação na indústria petroquímica - em especial aqueles observados a partir do início da década de 2000 — são explicadas com base no modelo proposto. A última 
seção do trabalho é usada para sistematizar suas principais conclusões e delinear uma tipologia de possíveis estruturas de mercado para a petroquímica nos próximos anos.

\section{FUNDAMENTAÇÃO TEÓRICA}

A análise dos movimentos de reestruturação observados no setor petroquímico pressupõe, inicialmente, a fixação de uma base conceitual para que esses movimentos sejam identificados e analisados. Autores que têm estudado movimentos de reestruturação em setores industriais, no período mais recente, os têm atribuído a um conjunto de "change forces" ou, nos termos usados neste artigo, "forças de mudança”. Para esses autores, "merger and restructuring are responses to strong forces of change, notably the increased pace of technological change and the globalization of the markets" (Weston et al., 1999a, p. 1). Esses mesmos autores, em outro trabalho (Weston et al., 1999b), indicam com mais detalhes as "forces" a que creditam os movimentos de reestruturação:

- mudança tecnológica (especialmente a revolução microeletrônica);

- globalização e livre-comércio;

- privatização e desregulamentação;

- instabilidade setorial;

- pressões por economias de escala, escopo e complementaridades; e

- preços ascendentes das ações, taxas de juros reduzidas e crescimento econômico vigoroso, na medida em que criam um ambiente favorável à realização de negócios e reestruturações.

Essas forças, em um plano mais geral, estão associadas às condições básicas de oferta, demanda e políticas públicas, como estabelecido no conhecido modelo estrutura/conduta/desempenho (ECD), mostrado de forma simplificada e adaptada na figura 1 e cuja origem é atribuída a Mason (1939).

Em sua formulação original, o modelo ECD pressupunha um encadeamento causal das condições básicas de oferta e demanda para a estrutura de mercado. A estrutura de mercado, por sua vez, definiria a conduta das firmas (estratégia) e o seu desempenho econômico (Scherer; Ross, 1990). Essa sequência está indicada na figura pelas setas mais escuras. Assim, por exemplo, o número de competidores (um dos elementos que compõem a estru- 
Figura 1: Modelo estrutura/conduta/desempenho

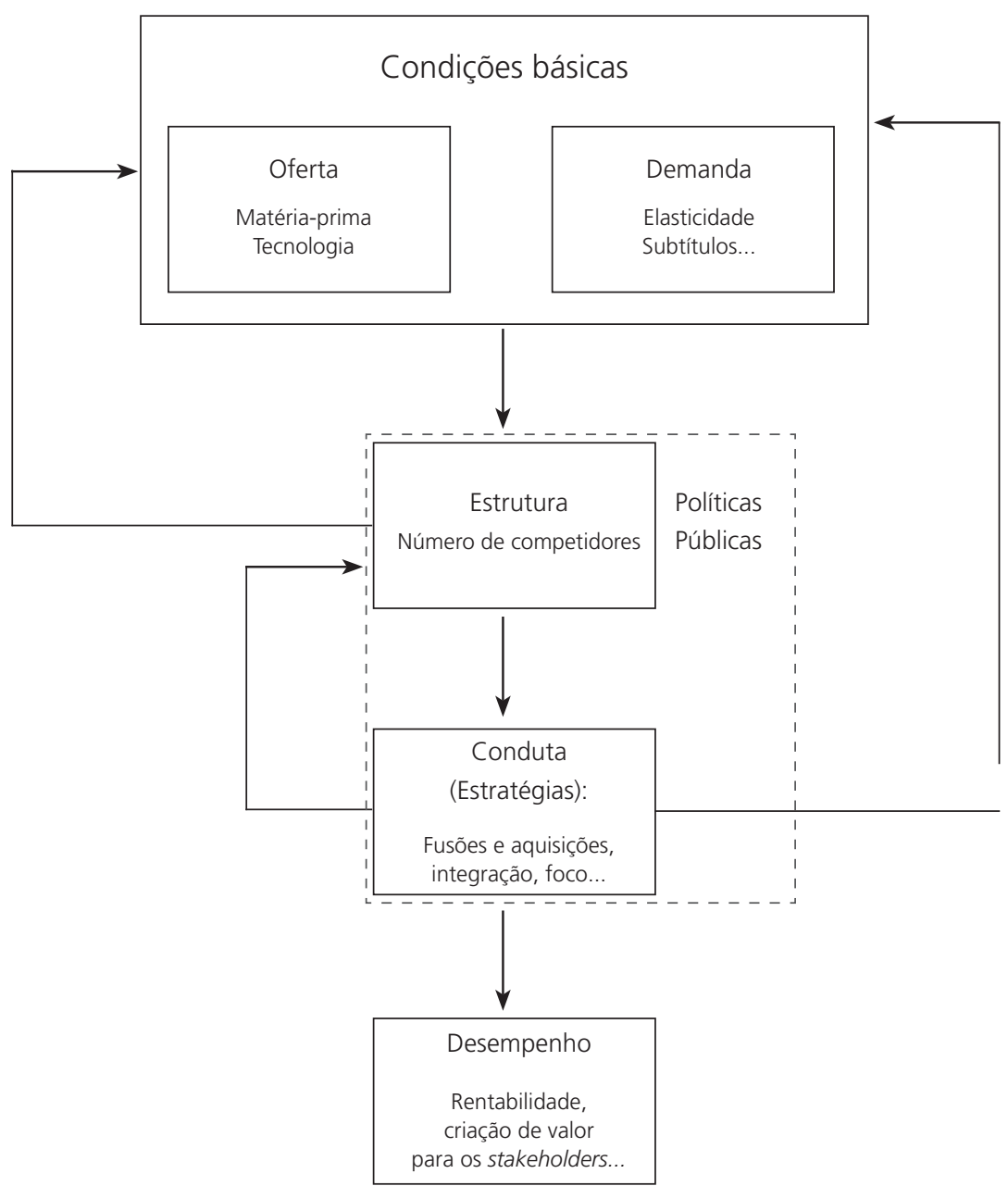

Fonte: Elaboração própria com base em Scherer e Ross (1990).

tura de mercado) orientaria as estratégias empresariais (integração vertical, fusões, aquisições, focalização, gastos em P\&D, marketing etc.), que, por sua vez, se refletiriam nos indicadores de desempenho da economia (eficiência produtiva, alocativa e pleno emprego) ou das firmas (rentabilidade e criação de valor). 
De acordo com Guerra (1994) e Teixeira (2005), o encadeamento causal e o tratamento das estruturas de mercado como independentes, que caracterizam o modelo ECD original, foram objeto de questionamentos por diversos autores. Segundo Guerra (1994), a desconsideração quase total de qualquer influência da estratégia da empresa e/ou do seu desempenho sobre a estrutura de mercado acarretava a não determinação das causas, por assim dizer, da própria estrutura, que se apresentava, desse modo, como algo dado exogenamente. Alie-se a isso a ausência da variável tempo e tinha-se a principal limitação do modelo: sua insuficiência do ponto de vista dinâmico, que não era total devido às contribuições teóricas feitas por Bain (1956) e Sylos-Labini (1956) a esse enfoque.

No conjunto desses questionamentos, destaque especial deve ser dado a Steindl e aos neoschumpeterianos. Para Steindl (1952), a acumulação interna de lucros das empresas, ao exercer uma influência positiva sobre as decisões de investir produtivamente, provoca uma pressão competitiva na estrutura de mercado, na medida em que o aumento da capacidade produtiva não é necessariamente acompanhado pela expansão do mercado. Quando este não cresce proporcionalmente, tem-se a eliminação de firmas ou a retração do investimento. Já os trabalhos neoschumpeterianos de Freeman (1974), Nelson e Winter (1977, 1982) e Dosi (1984) dão ênfase às condutas inovadoras, que seriam capazes de alterar as estruturas de mercado e a própria dinâmica econômica. Isso os leva a estabelecer uma espécie de via de mão dupla entre a estrutura e a conduta. Esse conjunto de relações bottom-up está indicado, na figura 1, pelas setas mais claras. Outra adaptação do modelo ECD original é o reconhecimento de que a estrutura e a conduta estão circunscritas pelas políticas públicas adotadas em cada país ou região (Scherer; Ross, 1990).

A compreensão do significado e dos determinantes das estruturas de mercado permite, então, uma melhor delimitação dos movimentos de reestruturação. Assim, as forças de mudança estão associadas às condições básicas de oferta e demanda, como estabelecido pelo modelo ECD original. Porém, com as adaptações sofridas por esse modelo, as políticas governamentais estão também na origem das forças de mudança, e as estratégias empresariais são, intrinsecamente, forças de mudança, pois contribuem para 
redefinir as estruturas industriais. Ocorre que forças dessa natureza estão se alterando permanentemente. Há, contudo, momentos históricos em que um conjunto delas é capaz de causar uma inflexão e motivar movimentos de reestruturação. Nesse sentido, distinguem-se o "processo de reestruturação" (contínuo no tempo, gerado pela evolução das forças de mudança) e o "movimento de reestruturação" (restrito a um dado tempo histórico e provocado por algumas forças de mudança que adquirem magnitude suficiente para motivar decisões de investimento e alterar a estrutura de mercado). Embora aparentemente tautológicas, as definições propostas evitam que movimentos de reestruturação sejam confundidos com o permanente processo de alteração das forças de mudança e/ou, exclusivamente, com fusões e aquisições que podem resultar em estruturas industriais mais integradas verticalmente e com maior grau de concentração. Assume-se, neste trabalho, que as estratégias adotadas pelas empresas incluem, entre outros aspectos, decisões sobre a formação de joint ventures, aproveitamento de spin-offs e implantação de novas unidades de produção.

Seguindo esse quadro teórico conceitual inicial, discutem-se, em seguida, as características estruturais da indústria petroquímica e seus padrões de comércio, com o intuito de propor um modelo analítico capaz de ser usado na análise dos recentes movimentos concretos de reestruturação nesse setor.

\section{ESTRUTURA E PADRÕES DE COMÉRCIO DA INDÚSTRIA PETROQUíMICA}

Para subsidiar a proposição do modelo de análise das decisões de investimentos no setor petroquímico, discutem-se, nesta seção, suas características estruturais e seus padrões de comércio. Assim, apresenta-se, inicialmente, uma visão geral das relações entre fornecedores e compradores nos diversos elos da cadeia produtiva, que começa com a extração de petróleo e gás natural e alcança a transformação de resinas termoplásticas e outros petroquímicos em produtos finais. Em seguida, discutem-se os aspectos de natureza tecnológica e os benefícios potenciais da integração entre a produção petroquímica e as atividades de refino. Essas características são empregadas para explicar a estrutura oligopolista do setor e as barreiras à entrada. A seção é encerrada com os padrões de comércio internacional que marcam o setor. 


\subsection{Aspectos estruturais}

\subsubsection{Relações com fornecedores e compradores}

As relações entre fornecedores e compradores na indústria petroquímica, indicadas esquematicamente na figura 2 , iniciam-se na indústria de hidrocarbonetos básicos extraídos do subsolo terrestre, especialmente petróleo e gás natural. Das refinarias e unidades de processamento de gás natural derivam produtos provenientes dessas matérias-primas, destacando-se a nafta, o gasóleo e o etano. São também relevantes os insumos propano e butano, obtidos no refino do petróleo, mas extraídos, majoritariamente, do processamento do gás natural. Desse conjunto de matérias-primas obtêm-se, então, os chamados petroquímicos de primeira geração ou petroquímicos básicos, subdivididos em olefinas (etileno e propileno, por exemplo) e aromáticos (benzeno etc.).

Os petroquímicos básicos tanto podem ser obtidos do gás natural, cuja produção dispensa os investimentos em refinaria, quanto da nafta e do gasó-

Figura 2: Relações entre fornecedores e compradores na indústria petroquímica ${ }^{3}$

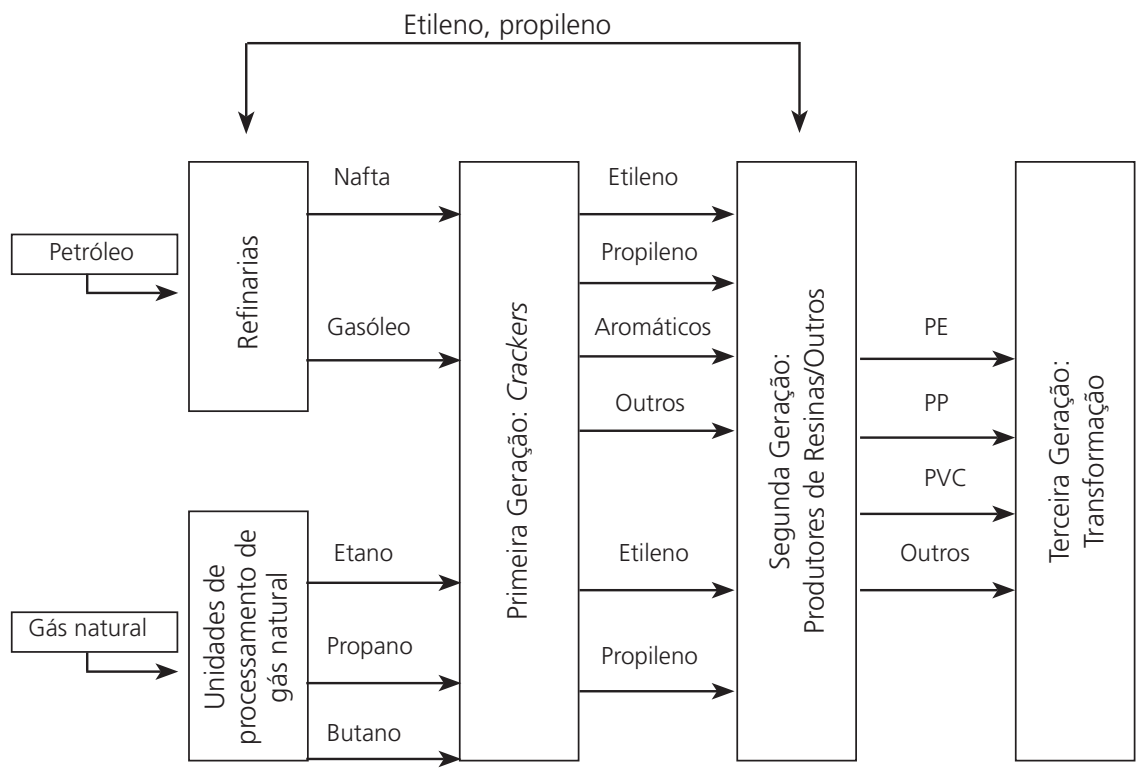


leo, que são subprodutos de refinarias. No caso da utilização do gás natural, o investimento requerido por tonelada de etileno é menor, mas, em compensação, ele é o único produto obtido. Já o uso da nafta, apesar de exigir um maior investimento por tonelada produzida de etileno, propicia a obtenção de outras olefinas (propileno, butadieno e butenos) e aromáticos. ${ }^{2}$

Quando oriundos da nafta, os petroquímicos básicos (primeira geração), divididos em olefinas e aromáticos, são obtidos em centrais de matériasprimas através de processos de quebra de moléculas (cracking). Na primeira geração, maior atenção é dada ao etileno e ao propileno. Como o etileno é pouco transacionável internacionalmente, exigindo transporte criogênico, que é dispendioso, análises de projetos de investimentos em plantas para sua obtenção ganham destaque na identificação das tendências da indústria petroquímica, pois tais projetos contemplam, quase sempre, algum tipo de aplicação downstream. A escolha de uma ou de outra trajetória em um determinado momento dependerá, entre outros fatores, da existência de reservas de gás natural, relação entre preço da nafta e do gás natural, custos de equipamento e demanda por produtos associados a preços remuneradores. Essas distintas alternativas, em variadas circunstâncias, propiciam vantagens competitivas diferenciadas. Em períodos de grandes excedentes de produtos petroquímicos, quando seus preços caem, as exportações dos derivados de etileno oriundas de países que utilizam o gás natural como principal matéria-prima petroquímica (EUA, Canadá, Oriente Médio) são favorecidas.

Os petroquímicos de primeira geração são insumos para a elaboração dos chamados petroquímicos de segunda geração. Esses produtos podem ser genericamente segmentados em resinas plásticas (termoplásticos e termorrígidos), elastômeros, tensoativos, solventes e fibras sintéticas. Nesse conjunto, destacam-se, em termos de volumes de produção, as resinas plásticas e os elastômeros. Tecnicamente, as resinas termoplásticas são aquelas que amolecem a partir do aquecimento e que podem, portanto, ser moldadas, solidificando-se e adquirindo uma nova forma após o resfriamento. São consideradas resinas termorrígidas aquelas que não se fundem e são moldadas submetendo-se à temperatura e à pressão. Os elastômeros (ou borrachas), por sua vez, são materiais capazes de se recuperarem de grandes transformações rápida e energeticamente. Os produtos de segunda geração ligam, a jusante, a petroquímica a diversas indústrias de transformação (ter- 
ceira geração) que dão origem a distintos produtos de consumo final e peças técnicas que são usadas em outros bens de consumo (automóveis, por exemplo).

\subsubsection{Tecnologia, relação capital/trabalho e escalas operacionais}

No que diz respeito à tecnologia, desde sua origem e durante seu desenvolvimento, a petroquímica associa-se a descobertas de laboratório. Suas empresas líderes possuem uma tradição de compromisso de longo prazo com atividades de pesquisa e desenvolvimento ( $P \& D$ ) de produtos e processos, por meio da montagem de laboratórios e programas de pesquisa próprios e do estabelecimento de fortes ligações com as universidades. A crescente maturidade tecnológica do setor, contudo, tem motivado uma redução dos investimentos em pesquisa básica e uma crescente atenção às atividades de pesquisa aplicada e de desenvolvimento experimental, através das quais pode-se "descommoditizar" produtos e, assim, obter maiores margens de lucro (Cavalcante, 1998).

Quanto às escalas operacionais e à relação capital/trabalho, alguns traços básicos do processo produtivo petroquímico devem ser ressaltados para que elas possam ser compreendidas. Ao exigir elevadas pressões e temperaturas e ao elaborar produtos altamente tóxicos e corrosivos, a petroquímica necessita de um sistema de produção sem intervenção direta do homem e com um controle de processos de alta precisão. Esses aspectos do sistema produtivo dão lugar a uma outra característica do setor: sua elevada relação capital/trabalho. Os custos de mão de obra não são expressivos quando comparados aos custos com capital e matérias-primas. Em particular, os custos com matérias-primas tornaram-se ainda mais relevantes após os choques do petróleo (Guerra, 1993).

A situação anterior aos choques do petróleo, marcada pela elevada participação dos custos fixos nos custos totais petroquímicos e pela rápida expansão da demanda, motivou um esforço tecnológico dirigido a crescentes economias de escala, levando ao crescimento acelerado das capacidades mínimas de produção consideradas competitivas. De fato, entre 1950 e 1970, a capacidade média de produção de uma planta de etileno na Europa Ocidental cresceu mais de 3.200\%, situando-se entre 400 a 500 mil toneladas por ano. Essa busca de economias de escala faz do tamanho dos mercados a se- 
rem atendidos uma variável fundamental para a lucratividade das operações, resultando daí uma forte instabilidade potencial, em períodos de mercados ofertantes, decorrente da geração de capacidade ociosa que leva à redução da utilização da capacidade.

\subsubsection{Integração entre a produção petroquímica \\ e as atividades de refino}

Há recorrentes evidências de que, de uma forma geral, a integração entre a produção petroquímica e as atividades de refino é uma alternativa atraente para agregar valor ao longo da cadeia. Essa agregação de valor persiste mesmo nas circunstâncias em que a elevação dos preços de petróleo reduz as relações de preços por tonelada dos produtos finais em relação a suas matérias-primas.

O resultado dessa característica estrutural é que maioria das plantas de etileno de grande porte que vêm sendo implantadas atualmente integra-se com atividades de refino (Nexant/Chem Systems, 2007). A Nexant/Chem Systems (2007) estimou uma redução dos investimentos fixos da ordem de 3 a 6\% e reduções não desprezíveis nos custos de produção decorrentes da integração refino-petroquímica. A redução do consumo de água e a reutilização de correntes de processo associam a integração a benefícios ambientais. Por fim, mas não menos importante, a integração permite um acesso privilegiado da petroquímica às matérias-primas oriundas da indústria petrolífera. Além da redução dos investimentos requeridos, a integração permite que eventuais resultados financeiros positivos da atividade de refino possam contrabalançar eventuais resultados negativos obtidos na produção petroquímica, e vice-versa. Nesse sentido, a integração reduz a volatilidade dos retornos sobre o capital e, portanto, os níveis de risco do investimento (Nexant/Chem Systems, 2007).

A alternância entre os ciclos de rentabilidade entre refino e petroquímica confirma o pressuposto de que a integração pode proporcionar retornos mais estáveis sobre o capital. Essa conclusão de caráter mais geral requer, contudo, alguma cautela em sua generalização, uma vez que a configuração das refinarias e o potencial de crescimento de mercado variam regionalmente, afetando, também, a atratividade da integração. Além dessa ressalva, não se deve desconhecer que unidades stand alone usualmente beneficiamse de mais foco e da concentração de know-how em áreas específicas. Além 
disso, as dificuldades de coordenação gerencial que resultam das diferenças de cultura organizacional entre as unidades (especialmente se advierem de empresas distintas) não devem ser desprezadas.

\subsubsection{Estrutura oligopolista e barreiras à entrada}

As características do processo petroquímico de produção, que envolvem alta intensidade de capital e elevadas economias de escala, além de erguerem barreiras à entrada no setor, explicam o fato de essa indústria já ter nascido oligopolizada. Sua gênese, nos EUA e na Europa, associa-se às grandes empresas atuantes nas indústrias química e petrolífera (Freeman, 1999).

Outra importante barreira à entrada vincula-se ao acesso à nafta e ao gás natural oriundos da indústria do petróleo. Mesmo considerando-se a existência de empresas petroquímicas que operam à base de contratos de fornecimento, a forma de acesso às matérias-primas pode inviabilizar o investimento, tanto pela questão de garantia de suprimento como pelo preço. Essa articulação técnica existente entre a indústria de petróleo e a então nascente indústria petroquímica contribuiu em muito para que as empresas petrolíferas decidissem investir na petroquímica.

Já o acesso à tecnologia não representa uma significativa barreira à entrada, uma vez que a oferta internacional de pacotes que cobrem desde a engenharia de processo, passando pela engenharia básica e de detalhamento, construção, montagem, até o próprio financiamento é relativamente ampla. Apesar disso, o domínio tecnológico se constitui em uma fonte de vantagem competitiva, uma vez que, em que pese a disponibilidade de tecnologias de processo passíveis de comercialização, a descommoditização de produtos, com o desenvolvimento de novos usos para as antigas resinas, e a busca de flexibilidade em termos de matérias-primas respondem pelos ainda relativamente elevados investimentos em $P \& D$ e reforçam os requisitos de maiores escalas empresariais no setor petroquímico (Arora, 1996; Arora et al., 2000).

Um dos principais traços de uma estrutura oligopolista é a existência de uma ociosidade planejada, na qual o investimento da empresa na ampliação da sua capacidade produtiva cresce à frente da demanda. Essa estratégia empresarial, usada como desestimuladora da entrada de novos concorrentes, inter alia, cria uma instabilidade potencial na petroquímica que se efetiva em momentos de baixa utilização relativa de capacidade instalada. 
Nesse tipo de estrutura de mercado, o grau de concentração é, usualmente, elevado. Apesar dessa elevada concentração, a abrangência da indústria petroquímica e a presença de diferentes tecnologias e/ou distintos graus de especialização na produção permitem a convivência de tamanhos de plantas e de empresas muito heterogêneas. Convivem grandes empresas altamente diversificadas e integradas com empresas de porte médio especializadas. Isso propicia uma dinâmica concorrencial não uniforme na petroquímica.

Tendo como fundamentação teórica inicial a revisão do modelo ECD, realizada na seção 1, e como base empírica as características estruturais da indústria petroquímica, apresentadas nesta seção, a próxima etapa consiste na proposição de um modelo analítico que possa ser usado na análise dos movimentos mais recentes de reestruturação do setor.

\subsection{Padrões de comércio internacional}

No que tange ao padrão de comércio internacional dos produtos petroquímicos, convém recuar à década de 1960 e início dos anos 1970 para que ele seja esclarecido. Naquela época, os países periféricos foram incorporados à expansão do setor, contribuindo, juntamente com os fluxos cruzados de investimentos entre países avançados, para tornar essa indústria extremamente globalizada. Apesar de o volume da produção destinada ao comércio internacional por cada produtor ser residual, como será visto adiante, os mercados de vários produtos petroquímicos, principalmente as resinas de segunda geração, tornaram-se integrados a tal ponto que os preços internacionais passaram a ser determinados por relações de oferta e demanda em escala mundial.

Por ser uma indústria de processo contínuo, as plantas petroquímicas mantêm todos os seus custos fixos, independentemente da capacidade produtiva utilizada. Por isso, busca-se ocupar a maior parte dessa capacidade com o atendimento dos mercados internos, praticando-se preços que cubram todos os custos e proporcionem uma margem compensadora. O mercado internacional, por sua vez, era visto como um escoadouro da produção residual, inclusive nos países que possuem grandes superavits comerciais de petroquímicos. Por esse motivo, o mecanismo de formação de preços dos produtos de grande tonelagem nesse mercado tem como parâmetro os preços marginais. Isso quer dizer que, para obter vantagens de es- 
cala, os produtores podem vender a fração de sua produção destinada ao mercado externo por um preço inferior aos seus custos totais, desde que igual ou superior aos seus custos variáveis. O diferencial entre preços internos e externos pode ser diretamente proporcional à proteção tarifária e não tarifária de cada país. Esse processo de formação de preços não se aplica aos países produtores de petróleo que não possuem mercados internos significativos (caso dos países árabes, por exemplo).

É possível deduzir do exposto que, em economias abertas, os produtores locais não podem transferir totalmente para os preços aumentos de custos que decorram de causas domésticas. Nesse contexto, as empresas multinacionais que possuem capacidades produtivas em diferentes localidades são capazes de variar a produção entre diversas plantas, adaptando-as às condições dos mercados locais e às mudanças nas taxas de câmbio. A dimensão global dessas empresas permite, ainda, que elas possam estabelecer estratégias de especialização na produção: um dado petroquímico pode ser produzido apenas em uma ou poucas localidades que passam a suprir as necessidades da empresa em outros mercados. Essa flexibilidade direciona as maiores empresas para a internacionalização, e suas respectivas participações no mercado global não se dão, necessariamente, por meio de grandes volumes de exportações. Pelo contrário, a competição no mercado global requer o estabelecimento de capacidade produtiva nos mercados estrategicamente mais atrativos.

\section{MODELO ANALÍTICO}

O modelo analítico proposto neste trabalho apoia-se na premissa de que algumas forças de mudança definem a estrutura da indústria e, dessa forma, fornecem elementos para a compreensão das estratégias empresariais, que envolvem, por exemplo, a propensão (ou não) de as empresas de petróleo se engajarem em movimentos de integração vertical para frente. Conforme indicado na seção 1, essas forças de mudança originam-se nas condições básicas de oferta e demanda e nas políticas governamentais pertinentes a cada atividade econômica. Já as estratégias adotadas pelas empresas refletem-se nos indicadores de desempenho e impactam, retroativamente, a estrutura. Nesse sentido, as estratégias empresariais são consideradas também uma força de mudança (figura 3 ). 
Figura 3: Forças de mudança e estrutura da indústria

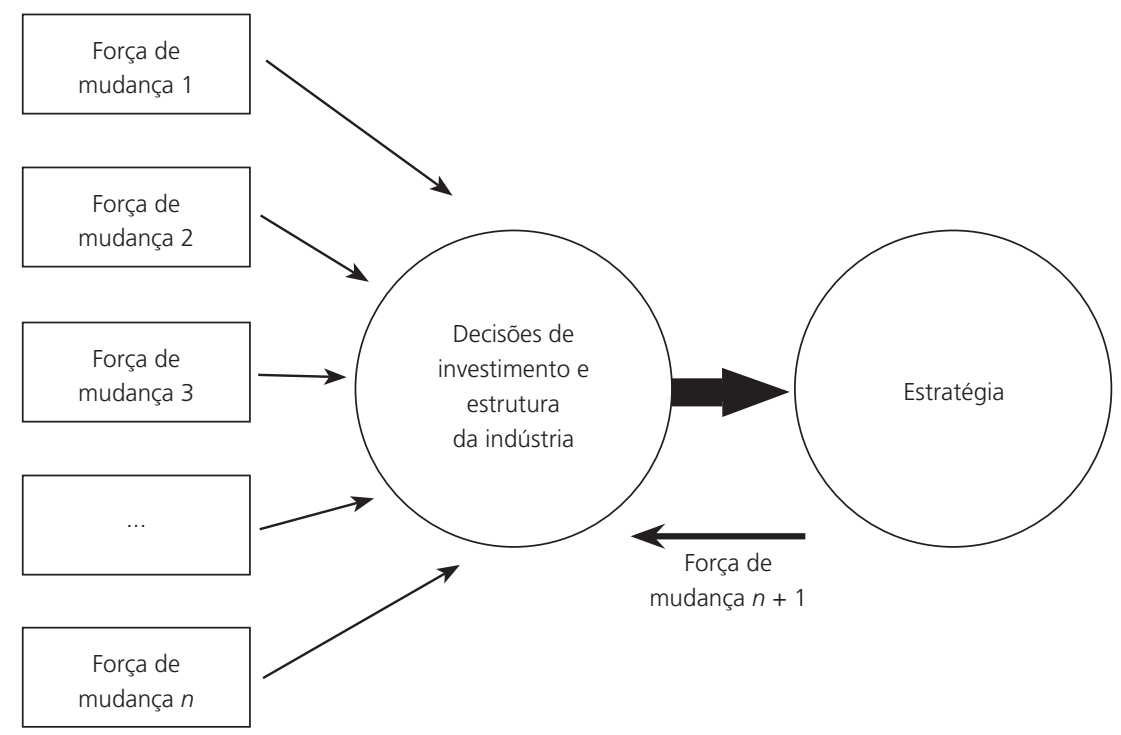

Fonte: Elaboração própria.

A figura 3 indica a sequência do modelo analítico adotado que, embora evidentemente não se preste a testes econométricos, fornece elementos que norteiam a análise dos movimentos de reestruturação. Como se observa, trata-se de uma combinação do modelo ECD com as características estruturais e os padrões de comércio do setor petroquímico expostos na seção anterior. A análise dessas características permitiu que se identificassem as condições de oferta e demanda, as políticas governamentais e as próprias estratégias empresariais como fatores que ensejam o surgimento de forças capazes de orientar as decisões de investimentos e impactar a dinâmica da indústria.

\subsection{Condições de oferta}

\subsubsection{Acesso a matérias-primas}

Há evidências recorrentes de que os movimentos de integração e desintegração vertical têm sido largamente motivados pela disponibilidade ou por restrições de acesso a matérias-primas por parte dos produtores. ${ }^{4}$ Além de terem um peso significativo nos custos de produção (mesmo sendo decres- 
centes na medida em que se percorre a cadeia), as principais matérias-primas petroquímicas, especialmente o etileno, são caracterizadas pela dificuldade de transporte a longas distâncias. Dessa forma, o acesso seguro a fontes de matérias-primas baratas e de qualidade é um fator primordial de competitividade.

Devido ao seu baixo custo, o gás natural vem sendo usado em escala cada vez maior na produção de petroquímicos. O crescimento das empresas dos países árabes, a exemplo da Sabic (Arábia Saudita), que ocupava, em 2006, o décimo primeiro lugar no ranking das empresas do setor químico ordenadas pelo faturamento publicado anualmente pela Chemical \& Engineering News, vem se dando, principalmente, pela via do gás natural, seja mediante investimentos próprios, seja em parceria com empresas petroleiras e petroquímicas. Além disso, o emprego de outras matérias-primas (etanol), bem como de tecnologias modificadas, como metanol para olefinas e Deep $\mathrm{Ca}$ talytic Cracking (DCC), tem sido anunciado.

\subsubsection{Crescimento da oferta}

Como regra geral, pode-se afirmar que a oferta de petroquímicos cresce em saltos ascendentes. Essa característica é consequência do fato de que a capacidade instalada não pode acompanhar, no mesmo ritmo, o crescimento da demanda devido às características tecnológicas da indústria. Dessa forma, a implantação de novas unidades e/ou a ampliação de unidades existentes dependem da rentabilidade oferecida pelos investimentos, em certo período. Quando postos em funcionamento, o incremento da oferta deprime a rentabilidade, devido à queda de preços, levando a curva de ciclo ao seu ponto mais baixo (figura 4). Nessa fase, a oferta é também regulada por taxas de operações menores (capacidade efetivamente utilizada). Estima-se que o ciclo de negócios nessa indústria teria a duração de oito anos: quatro anos de preços, rentabilidade e taxa de operação mais elevados e quatro anos de preços, rentabilidade e taxa de operação mais baixos.

\subsubsection{Mudanças tecnológicas}

A petroquímica é considerada uma indústria madura, com uma tendência a reduzir seus investimentos em desenvolvimento tecnológico. ${ }^{5}$ Mesmo assim, não é possível subestimar o papel da tecnologia para a competitividade 
Figura 4: Modelo para caracterização dos ciclos de negócios na petroquímica

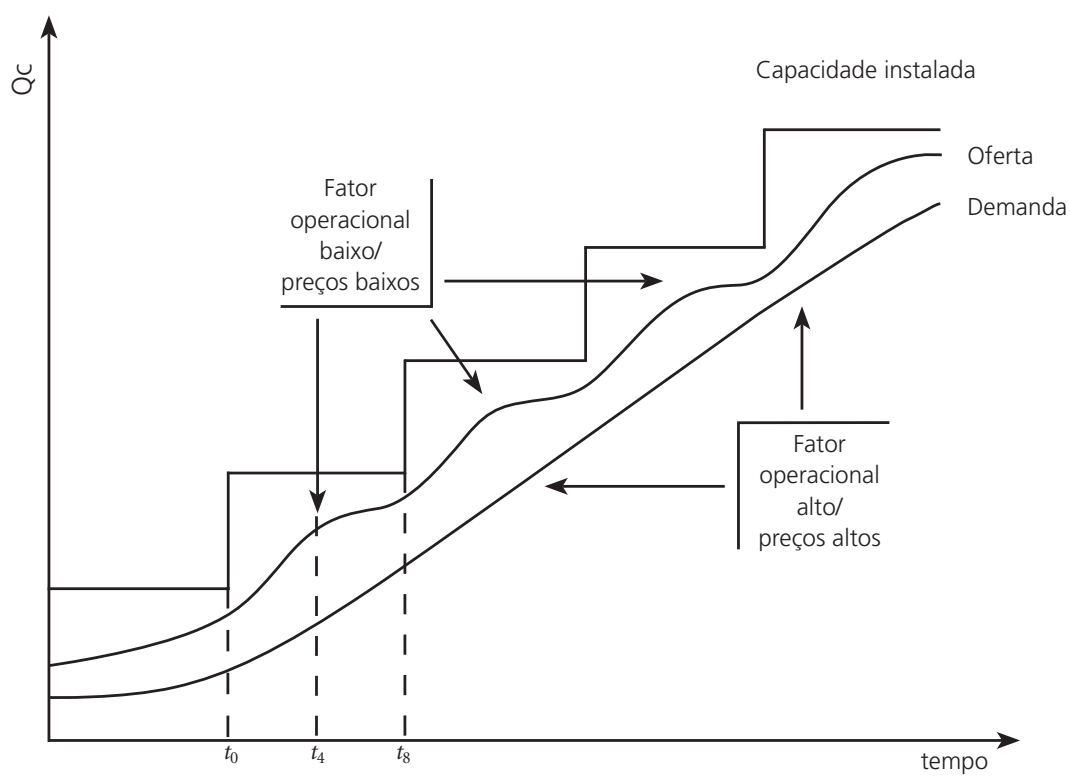

Fonte: Elaboração própria.

no setor. De fato, com o acirramento da competição, as empresas procuram, pela via da inovação, manter, renovar ou expandir suas posições de mercado. Diante disso, as seguintes tendências tecnológicas devem ser observadas (Teixeira, 1985; Rocha e Teixeira, 1995; Cavalcante, 1998; Arora, 1996; Arora et al., 2000).

- A crescente maturidade tecnológica do setor petroquímico levou a competição por inovações de produtos para o campo do desenvolvimento de aplicações, através de copolímeros, blends, aditivação e compostagem. Novos aditivos e cargas, incluindo nanocargas, são alguns dos meios utilizados.

- Desenvolvimento de matérias-primas alternativas à nafta e ao gás natural, com particular ênfase no segmento alcoolquímico e seus impactos sobre a viabilidade econômica da produção de polietileno a partir do etileno do álcool.

- Desenvolvimento de tecnologias de craqueamento de petróleo pesado.

- Sistemas catalíticos alternativos, principalmente aos da família Zigler-Nata para a polimerização de olefinas, enfatizando as ameaças e oportunidades associadas à difusão dos catalisadores metalocênicos. 
- Desenvolvimento tecnológico em setores intensivos em ciência (biotecnologia e nanotecnologia), focando seus impactos na produção petroquímica.

- Biopolímeros, com ênfase em polímeros biodegradáveis.

- Novas demandas ambientais, que incluem a reciclagem de resinas e outros produtos petroquímicos.

Sabe-se que o recurso ao licenciamento de tecnologias ainda é largamente utilizado no setor. Em face dos desdobramentos da competição por inovações cabe, entretanto, questionar até que ponto os novos entrantes — principalmente aqueles localizados em regiões sem tradição em $\mathrm{P} \& \mathrm{D}$ - poderão concorrer com os tradicionais produtores, mesmo nos mercados de commodities, em que o desempenho depende da capacidade de acompanhar os desenvolvimentos tecnológicos e de introduzir inovações, ainda que incrementais.

\subsection{Condições de demanda}

\subsubsection{Crescimento da demanda}

Quando analisado em função da evolução da renda a longo prazo, o comportamento do consumo de um produto petroquímico pode ser descrito por uma curva "S". Isso equivale a dizer que a elasticidade da demanda em relação ao PIB não se mantém constante ao longo do tempo: à medida que o produto "amadurece", a evolução do consumo, como proporção do crescimento da economia, decresce. Dessa forma, como regra geral, quanto antes foi iniciada a comercialização de um produto em um dado mercado, menor é a sua elasticidade atual em relação ao crescimento do PIB. Assim, o ritmo de crescimento da demanda pode ser diferente em cada mercado. Essa regra geral pode ser relaxada caso surjam avanços tecnológicos (que permitam um determinado produto capturar novos mercados) ou restrições de ordem ambiental.

Atualmente, a expansão da demanda mundial está sendo puxada, principalmente, pelo crescimento econômico nos países da Ásia (particularmente China e Índia). Nesse caso, cabe observar o ritmo desse crescimento e o horizonte de tempo durante o qual ele persistirá. É importante observar que o comportamento dessa demanda tem influenciado enormemente a confi- 
guração do atual ciclo dos negócios e pode, caso se mantenha o seu crescimento, reconfigurar os modelos utilizados para a construção de cenários de longo prazo para a indústria.

\subsubsection{Acesso a mercados}

Apesar da crescente globalização da indústria, muitos mercados nacionais — principalmente aqueles localizados em países que são novos entrantes ainda possuem barreiras alfandegárias. Além disso, os custos de transporte e logística funcionam como barreiras não alfandegárias muitas vezes difíceis de serem superadas por produtores internacionais. Some-se a isso o fato de que, no caso de petroquímicos finais (resinas, elastômeros, fios etc.), a proximidade do produtor com o mercado/cliente, inclusive para facilitar a prestação de assistência técnica e o desenvolvimento de soluções, é um importante fator de competitividade. Assim, se, por um lado, a proximidade da fonte de matérias-primas é fundamental, por outro, o acesso a mercados e clientes de produtos finais pode ser decisivo para definir posições na arena competitiva.

Cabe, então, indagar se os movimentos de integração vertical e focalização em core business são, em alguma medida, guiados pela lógica de acesso a mercados relevantes, provocando uma descentralização da produção, ou se, alternativamente, pode estar ocorrendo um movimento oposto: a concentração da produção nos países produtores de matérias-primas, ainda que não possuam mercados internos de peso.

\subsubsection{Possibilidades de substituição}

A competição intermateriais, uma das características mais marcantes do setor petroquímico, tem, em grande medida, condicionado sua trajetória tecnológica, bem como a demanda. $\mathrm{O}$ fenômeno não se limita aos plásticos versus materiais tradicionais, envolvendo, também, as resinas plásticas, uma vez que mais de uma resina pode ser usada na mesma aplicação (Bomtempo, 2001). Dois outros desenvolvimentos tecnológicos, com importantes impactos sobre as possibilidades de substituição entre resinas, devem também ser mencionados:

- a emergência e difusão dos plásticos de engenharia. Essa família de produtos possui alto valor agregado e grande poder de substituir matérias 
tradicionais, além de ser empregada em novas aplicações, ampliando o mercado das resinas petroquímicas; e

- o surgimento de uma família de novos produtos, chamados genericamente de elastômeros termoplásticos. A grande vantagem desses produtos é que eles permitem a produção de peças de borracha por meio das técnicas de processamento rápido utilizadas em termoplásticos, adicionado ao fato de possibilitar a reciclagem sem perda das propriedades dos materiais.

Desse modo, é importante que se observem os condicionantes tecnológicos, ambientais e de mercado que circunscrevem as possibilidades de substituição entre resinas termoplásticas, uma vez que essas possibilidades orientam as decisões de investimentos no setor.

\subsection{Políticas governamentais}

Apesar de ser uma indústria há muito globalizada, os investimentos na petroquímica ainda são condicionados pelo ambiente institucional que circunscreve as estratégias adotadas pelas empresas. Políticas industriais de atração de investimentos e/ou políticas comerciais de proteção aos produtores locais desempenham papel importante nas configurações regionais do setor. Com efeito, países com mercados internos relativamente grandes não prescindem, usualmente, de uma oferta local, mesmo que a estrutura de custos não seja favorável.

As políticas governamentais voltadas para a atração e proteção dos investimentos, a regulamentação ambiental, bem como as que afetam fontes privadas e públicas de financiamento podem desencadear importantes forças de mudança no setor. Neste último aspecto, vale destacar a importância crescente dos chamados investidores institucionais (fundos de pensão e de investimentos) nos mercados financeiros internacionais, tema amplamente discutido na literatura econômica, e, mais recentemente, os chamados fundos soberanos. Esses investidores e fundos soberanos, além de reunirem volumes significativos de recursos, sendo, portanto, vistos pelas empresas como uma importante fonte de financiamento, têm, ao longo das duas últimas décadas, adquirido um número crescente de ações de empresas de diversos setores econômicos, e como acionistas, ainda que minoritários, mostram-se capazes de pressionar os executivos dessas empresas para me- 
lhorarem sua performance financeira, gerando, assim, retorno para seus cotistas, uma vez que firmas muito diversificadas podem ser vistas como mais difíceis de serem acompanhadas e de terem seu desempenho avaliado. Nesse contexto, torna-se necessário observar até que ponto a disponibilidade desses recursos incentiva, por um lado, movimentos de integração vertical, e os padrões de governança adotados pelos gestores desses fundos influencia, por outro, a adoção de estratégias de focalização.

\subsection{Estratégias empresariais}

O modelo analítico proposto neste trabalho pressupõe que, para subsidiar suas decisões de investimento e formular suas estratégias competitivas, as empresas que atuam na indústria petroquímica analisam, constantemente, as variáveis identificadas nas subseções precedentes, pois elas podem desencadear significativas forças de mudança. No entanto, as estratégias possuem certa autonomia com relação à estrutura de mercado na qual as empresas se inserem. De fato, as firmas se diferenciam umas das outras e "fazem suas apostas". Dessa forma, as estratégias são influenciadas e influenciam a estrutura da indústria e se constituem em uma força de mudança endógena. A análise das estratégias pode ser feita, por exemplo, a partir de uma tipologia que segmenta as empresas líderes com atuação no setor petroquímico em três tipos:

- petrolíferas com atividades petroquímicas relevantes;

- empresas com atividades diversas, focalizadas ou não, na indústria petroquímica; e

- empresas químicas/petroquímicas de especialidades.

A tipologia proposta apoia-se largamente na posição ocupada pela empresa nos diversos segmentos da indústria química, indicados esquematicamente na figura 5 .

Assim, as estratégias empresariais envolvem, dentre outros componentes, movimentos ao longo da cadeia de valor, em direção a um extremo ou a outro. Esses movimentos resultam de análises dos diversos segmentos da indústria, com base no comportamento das forças de mudança, e da busca de respostas para questões como as identificadas a seguir:

- Como os concorrentes estão se posicionando ao longo da cadeia de valor? 
Figura 5: Descrição dos segmentos

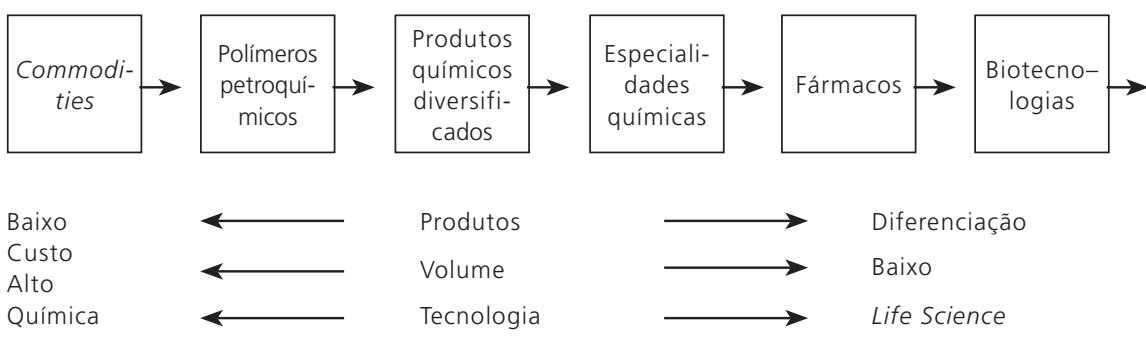

Fonte: Wilcox (2003, p. 5).

- O que justifica suas opções de integrar, permanecer ou abandonar segmentos?

- Qual o mix de ativos predominante?

- Há algum novo player emergente, em um dado segmento, que pode ser mais exitoso do que players tradicionais? Onde se localiza sua vantagem competitiva?

- Em que segmentos o retorno sobre os ativos tem se mostrado mais elevado?

Diante das limitações tecnológicas intrínsecas aos processos de produção petroquímica, pode-se inferir que as melhores oportunidades surgirão para os produtores capazes de:

- vender a maior parte de sua produção em mercados dinâmicos e próximos das unidades produtivas;

- ter acesso a matérias-primas baratas e abundantes, inclusive pela via do desenvolvimento tecnológico de alternativas;

- diferenciar produtos e ofertar especialidades.

Dessa forma, um elemento-chave na posição competitiva será, portanto, a adoção de estratégias que assegurem presença nos mercados dinâmicos e baixo custo de produção de petroquímicos básicos (principalmente etileno e propileno, por serem de maior demanda, conforme a figura 2). Essas questões, que têm motivado tanto a realização de mudanças internas nas áreas de gestão como a promoção de modificações externas (fusões, aquisições, desinvestimentos, spin-offs) pelas empresas do setor, mostram, naturalmen- 
te, contornos distintos, conforme o enquadramento das empresas na tipologia proposta neste trabalho:

- As empresas petrolíferas, como regra geral, vêm realizando um explícito movimento de integração (para frente) de suas atividades de refino com a petroquímica.

- Já as empresas com atividades diversas, focalizadas ou não na petroquímica, têm buscado uma integração para trás, em muitos casos, através do estabelecimento de joint ventures com empresas de petróleo. O objetivo principal é ter acesso a fontes de matérias-primas. Quando isso não é possível, procuram focar suas atividades em negócios nos quais possuam reconhecidas vantagens competitivas (tecnologia superior, expressiva parcela de mercado e expertise mercadológica e/ou operacional).

- Por fim, as empresas de especialidades químicas/petroquímicas têm procurado aprofundar movimentos de diversificação, especialmente em direção às chamadas ciências da vida, apoiados, basicamente, em desenvolvimentos tecnológicos.

A aplicação do modelo analítico aqui proposto permite não apenas a compreensão dos movimentos de reestruturação observados na indústria petroquímica mundial, mas também a construção de cenários prospectivos brevemente mencionados na conclusão deste trabalho.

\section{CONCLUSÕES}

Neste artigo, propôs-se um modelo de análise das decisões de investimentos na indústria petroquímica destacando as principais variáveis que as têm motivado e induzido os movimentos de reestruturação no setor. A análise fundamentou-se em uma adaptação do modelo ECD, visando a incorporar novas visões sobre a dinâmica industrial, e nas características estruturais do setor petroquímico. Nesse sentido, o modelo usado adaptou novas visões sobre a dinâmica industrial ao arcabouço teórico estático proposto pelo modelo ECD para analisar a realidade da indústria petroquímica. Essa adaptação forneceu elementos que permitiram delinear uma tipologia de possíveis estruturas oligopólicas para essa indústria nos próximos anos. Acredita-se que os passos seguidos para realizar a adaptação aqui descrita possam 
ser replicados para outros setores, ampliando e conferindo mais robustez à metodologia utilizada.

A aplicação do modelo proposto permitiu concluir que, na indústria petroquímica, as decisões de investimentos e, consequentemente, a estrutura industrial que resulta dos efeitos dessas decisões são impulsionadas, principalmente, pelas estratégias empresariais e pela localização dos investimentos. As estratégias são condicionadas pelas forças de mudança e podem ser, basicamente, de duas naturezas: integração vertical e focalização em core business. Já a localização geográfica dos novos investimentos é orientada, principalmente, pelo acesso a matérias-primas e a mercados com elevados potenciais de crescimento.

Com relação às estratégias empresariais, as análises apresentadas ao longo deste trabalho indicam a predominância da combinação de concentração e integração, uma vez que tanto as empresas petroleiras se movimentam downstream, como as químicas diversificadas upstream, via fusões, aquisições e parcerias com empresas detentoras de reservas de petróleo e capacidade de refino, principalmente dos países do Oriente Médio e na China. Isso não quer dizer, contudo, que a estratégia de focalização em core business seja irrelevante. Porém, aquelas que adotam essa estratégia tendem, em geral, a se tornar empresas de especialidades, reduzindo, cada vez mais, seus ativos petroquímicos propriamente ditos. Em outras palavras, a adoção dessa estratégia leva a empresa a se posicionar em outro tipo de negócio, diferente do petroquímico. Já no que diz respeito à localização, pôde-se verificar a coexistência de movimentos de descentralização da indústria em relação às tradicionais regiões produtoras dos países ricos (especialmente América do Norte e Europa) e centralização no Oriente Médio e na Ásia.

Ao se cruzarem os dois atributos que podem assumir as forças de mudança consideradas mais significativas, pode-se visualizar uma estrutura, no que se refere à indústria petroquímica, na qual convivem um "oligopólio condensado" (verticalmente integrado e geograficamente concentrado em tradicionais regiões produtoras) e um "oligopólio descentralizado" (verticalmente integrado, porém marcado pela descentralização das tradicionais regiões produtoras dos países avançados em direção ao Oriente Médio e à Ásia). Persistindo, todavia, os padrões de investimentos que têm sido observados ao longo dos últimos anos, acredita-se que passe a predominar o "oli- 
gopólio descentralizado”. Por outro lado, no que diz respeito às especialidades, predominam as forças que levam a um "oligopólio desintegrado" (foco em core business geograficamente concentrado), embora com tendência a converter-se em um "oligopólio pulverizado" (foco em core business geograficamente desconcentrado), uma vez que, embora os investimentos nos segmentos tecnologicamente mais avançados tendam a se concentrar nos países ricos, assiste-se a movimentos, mesmo que lentos, de descentralização para regiões periféricas, tanto por meio de empresas multinacionais como por empresas do Terceiro Mundo que conseguem acesso às tecnologias relevantes. Assim, essas estruturas identificadas não são excludentes, uma vez que podem conviver e se interpenetrar, o que provavelmente acontecerá a médio prazo.

\section{NOTAS}

1. Ver, por exemplo, Arora e Landau (1999), Freeman (1999) e Swift (1999).

2. Diversos autores (Guerra, 1993; Cavalcante, 1998; Hiratuka et al., 2000) discutem em detalhes a cadeia produtiva da indústria petroquímica e suas implicações sobre os padrões de fornecimento e escoamento da produção.

3. É importante assinalar que essas relações podem ocorrer dentro de um mesmo grupo econômico.

4. Ver, por exemplo, Guerra (1993). Um exemplo recente foi a tentativa de formação de uma joint venture entre a Kuwait Petroleum Corporation (KPC) e a Dow. Enquanto a primeira buscava capturar expertise tecnológica e comercial, a segunda pretendia ter acesso a matérias-primas.

5. Ver Stobaugh (1988).

\section{REFERÊNCIAS BIBLIOGRÁFICAS}

ARORA, A. Patents, licensing, and market structure in the chemical industry. Working paper, 1996.

; CECCAGNOLI, M.; RIN, M. da. Corporate Restructuring and R\&D: a panel data analysis for the chemical industry. Set. 2000.

; LANDAU, R. The chemical industry: from the 1850s until today. Business Economics, v. 34, n. 4, out. 1999.

BAIN, J. Barriers to New Competition. Harvard University Press, Cambridge, MA, 1956.

BOMTEMPO, J. V. A competição em plásticos de engenharia. Rio de Janeiro: Finep, 2001. 
CAVALCANTE, L. R. M. T. Maturidade tecnológica e intensidade em pesquisa e desenvolvimento: o caso da indústria petroquímica no Brasil. Salvador: Fieb, 1998.

DOSI, G. Technical Change and Industrial Transformation: the theory and an application to the semiconductor industry. Londres: Macmillan, 1984.

FREEMAN, C. The economics of industrial innovation. Londres: Penguin, 1974.

FREEMAN, R. D. The chemical industry: a global perspective. Business Economics, v. 34, n. 4, out. 1999.

GUERRA, O. F. Competitividade da indústria petroquímica (Estudo da competitividade da indústria brasileira/nota Técnica Setorial do Complexo Químico). Campinas: IE/Unicamp - IEI/UFRJ - FDC - Funcex, 1993.

_- Estrutura de mercado e estratégias empresariais: o desempenho da petroquímica brasileira e suas possibilidades futuras de inserção internacional. Brasília: Sesi-DN, 1994.

HIRATUKA, C.; GARCIA, R.; SABBATINI, R. Limites e possibilidades do Brasil nas configurações produtivas globalizadas: a indústria petroquímica. Araraquara e Campinas, 2000. (Relatório Final de Pesquisa.)

MASON, E. Price and Production Policies of Large-Scale Enterprise. American Economic Review, v. 29, n. 1, p. 61-74, 1939.

NELSON, R.; WINTER, S. An Evolutionary Theory of Economic Change. Cambridge, MA: Harvard U. P., 1982.

In search of useful theory of innovation. Research Policy, North Holland, n. 6, 1977.

NEXANT/CHEM SYSTEMS. Benefits of refinery/petrochemical integration. Perp Report 06/07S7, set. 2007.

ROCHA, F. N. N.; TEIXEIRA, F. L. C. Estratégia tecnológica na petroquímica brasileira. RAUSP - Revista de Administração da Universidade de São Paulo, v. 30, n. 2, 1995.

SCHERER, F. M.; ROSS, D. Industrial market structure and economic performance. 3. ed. Boston: Houghton Mifflin, 1990.

STEINDL, J. Maturidade e estagnação no capitalismo americano. São Paulo: Abril Cultural, 1983 (Os economistas). 1. ed., 1952.

STOBAUGH, R. Innovation and Competition: the global management of petrochemical products. Boston: Havard Business School Press, 1988.

SWIFT, T. K. Where is the chemical industry going? Business Economics, v. 34, n. 4, out. 1999. SYLOS-LABINI, P. Oligopólio e progresso técnico. São Paulo: Forense, 1956.

TEIXEIRA, F. L. C. Estruturas de mercado e competitividade industrial: breve referencial teórico. Bahia Análise e Dados, v. 14, n. 4, p. 745-754, 2005. 
; The political economy of technology learning in the Brazilian petrochemical industry. 1985. 316 f. Thesis (Doctor of Philosophy) — Science and Technology Policy Research (SPRU), University of Sussex, Brighton, 1985.

WESTON, J. F.; JOHNSON, B. A.; SIU, J. A. Mergers and Acquisitions in the Global Chemical Industry. Business Economics, v. 34, n. 4, out. 1999a.

; Mergers and restructuring in the world oil industry. Journal of Energy Finance and Development, v. 4, p. 149-183, 1999 b.

WILCOX, B. A. Economics forces restructuring the chemical industry. SRI Consulting PEP Review, n. 4, 2003, dez. 2003. 
